\title{
SOCIAL ORGANIZATIONAL RESPONSIBILITY MANAGEMENT MODELS: WHAT LESSONS FOR HUMAN RESOURCES MANAGEMENT?
}

\author{
Marie-Pier Côté ${ }^{1}$, Doina Muresanu² \\ 1,2 Management Department, Université du Québec en Abitibi-Témiscamingue, \\ Rouyn-Noranda, CANADA \\ marie-pier.cote2@uqat.ca \\ doina.muresanu@uqat.ca
}

\begin{abstract}
This communication represents a work in progress by the first author, who is enrolled in a research program of master in organizations management. The notion of social corporate responsibility (SCR) is increasingly present in management literature. It is linked to profitability, investor attraction and brand image. More recent research has begun to investigate the link that can be made between SCR and human resources management (HRM). In the vein of this field of research, our paper proposes to take a closer look at how certain SCR models, implemented consciously or not by certain companies, could impact the employee perception of employment relationship quality. The concept of "quality of life at work" and social identity theory will be used to measure the employment relationship quality. To carry out the research, a qualitative methodological approach, based on comparative case study, will be used. A sample of about 20 participants (manager and employees) will be targeted. The results of the research could provide a better understanding of how the decisions taken in relation to SCR could be combined to form original models of social responsibility management. Moreover, the study of the links that can be established between SCR models and the perception of the employment relationship quality could allow companies to better manage their human resources and improve retention and attraction of the employees.
\end{abstract}

Keywords: social corporate responsibility (SCR), social identity theory, quality of life at work, employment relationship quality

\section{JEL Classification: M12 Personnel Management}

\section{Introduction}

We are currently experiencing great upheavals in the work environement all over the world. Indeed, the COVID-19 pandemic will have forced organizations to adapt to a whole new reality. People-to-people contact should be minimized and strict sanitary measures applied to allow organizations to continue operating. All of these measures are the result of new laws and procedures related to the pandemic and they all aim to protect employees. (CNESST, 2020).

Despite this major element that businesses had to face, the labor shortage in Canada, and the Quebec region Abitibi-Témiscamingue would be particularly affected. (Desjardins, 2019). According to Statistics Canada, the region's unemployment rate stood at $4.5 \%$ in August 2020, the lowest unemployment rate in the country. This labor shortage affects businesses, employees and citizen services. For organizations, the effects of the labor shortage can translate into lower productivity, reduced hours of operation, an inability to innovate and, by the same token, lower revenues and reduced overall performance. Also, a shortage of human resources forces employers to make maximum use of the resources in place. This excessive use can lead to more burnout and repeated absence for employees.

Corporate social responsibility (CSR) could play a key role in responding to these upheavals in the world of work. Corporate social responsibility is a concept little known to employees and even employers (Gilbert and Greffet, 2019). The difficulty of agreeing on a common 
definition of the concept gives an idea of the extent of the differences surrounding it (Baba, 2017, Pereira, 2014). One of the definitions most often cited in the literature is that of Carroll (1979) who argues that CSR encompasses a company's economic, legal, ethical and voluntary expectations of organizations at a given point in time. CSR could then be seen as, for example, the commitment of the organization that goes beyond simply satisfying the interests of shareholders, to take care of several of its stakeholders.

Indeed, CSR could be seen as a lever for attracting the workforce through the positive image it conveys. On the other hand, could the social responsibility of organizations play a role in employee retention? According to Schill, Letheilleux, Godefroit-Winkel and Combes-Joret (2018), an important stream of research in human resources management has been built on the perception of employees regarding the social responsibility of their organization. The various issues experienced in the workplace could increase the interests of organizations in ensuring a good employment relationship.

We would like to highlight the links that may exist between CSR and the quality of the employment relationship. Could the CSR management models applied in organizations have an uncommon effect on the perception of the employment relationship? Could the temporality, the importance given to measures and the social pressure influence the perception of the employment relationship of employees? This particular concept is little studied in the literature and could provide indications as to the possibility of using CSR in a context of perceived quality of employment relationship. From this point of view, can we assume that the quality of the employment relationship could be considered as an element of retention and loyalty of the workforce. This research proposes to link the implementation of corporate social responsibility with the employment relationship of employees.

The employment relationship is defined as the bond that an employee, an individual, weaves with his organization, its representatives, and its members (Coyle-Shapiro et al., 2005). To better understand the employment relationship, we have chosen to study in more depth the perceptions of employees regarding their organizational identification and the quality of life at work offered in their environment.

Despite efforts to manage CSR, it may be perceived differently by employees. Will the employees we interview have a favorable perception of their quality of work life when CSR measures are applied in the workplace? We therefore wish to answer the following research question: What would be the influence of corporate social responsibility management models on employees' perception of the quality of their employment relationship?

The answer to our research question could show both scientific and social relevance of our research. The scientific relevance is to deepen the study of the links that may exist between CSR models and social identity as well as the quality of life at work. At the social level, research enables companies to become aware of the fact that commitments to social responsibility could allow them to position themselves as the employer of choice and for employees, this means better employment relations.

We will first present the conceptual framework and a research model. Subsequently, we will establish an operating framework.

\section{Proposal for a research model}

To answer the research question, we will first present the literature review on the social responsibility of organizations as well as that of the theory of social identity and quality of life at work. These two elements will allow us to link CSR with the perception of the employment relationship quality. 


\subsection{Corporate social responsibility}

The proliferation of CSR measures today allows us to question the very definition of corporate social responsibility. What exactly is it? Several authors in the scientific literature offer us definitions of the concept (for example, Carroll, 1979, Turcotte, 2018).

As part of this research, we decided to retain three established models of CSR and a proposed research model that we will call the integrative model. This will allow us to define our model of corporate social responsibility.

\subsubsection{The Carroll model}

In the scientific community, the measurement of CSR has mainly developed through theories of the societal performance of the company (PSE) (Gond and Igalens, 2018). To define the performance models of social responsibility, we must first understand the threedimensional conceptual model of Carroll (1979) which is widely disseminated in the scientific literature. Indeed, the author suggests that it is the following three distinct aspects that must be defined and interrelated, namely: a basic definition of social responsibility, an enumeration of the issues for which social responsibility exists and finally, a specification of social responsibility. response philosophy.

The model also shows four levels of responsibility that society expects from companies. Each responsibility, individually, is just one part of CSR. The four levels are part of the very definition of CSR, namely, the economic, legal, ethical, and voluntary level (Carroll, 1979, p.500).

\subsubsection{The Pasquero model}

Pasquero (2018), proposes to develop an open model that could evolve over time, while being concerned with the history of the concept of corporate social responsibility. All the dimensions currently covered in the different concepts or definitions of CSR are present in this model. Also, it is important to specify that for Turcotte, the model must be connective, that all the elements included in the model must be minimally satisfied.

Briefly, the Pasquero (2018) model includes eight components of CSR: efficient management (ensuring the sustainability of the organization and the competence of managers); ethical rectitude (making ethics the basis of governance), philanthropy (donations, scholarships, etc.), social receptivity (organizational innovation and adaptation to changes), caring (responsible human resources management), nuisances limitation (material and psychological), accountability (transparent company, triple balance sheet) and citizen participation (involving surrounding communities in decision-making within the company). Moreover, this model will be used a lot in the present research.

\subsubsection{The ISO 26000 Standard}

The model of the ISO 26000 standard seeks to establish two fundamental practices of social responsibility. First, the organization must identify its social responsibility and the stakeholders in its environment. Subsequently, the standard proposes to be based on seven central questions of CSR, namely, human rights, relations and working conditions, the environment, fair practices, questions relating to consumers and finally the community and local development.

Therefore, the ISO 26000 standard sheds interesting and relatively current light on corporate social responsibility. The integrating model that we present in the Research model section will be an amalgamation of the various models presented earlier and the characteristics that we considered important. To better serve the objectives of our research, we plan to take into account certain elements that we retain from the literature review on the subject of corporate social responsibility and transpose them into an original model of CSR management. 


\subsubsection{The integrative research model}

Following the literature review, we want to design an integrative CSR management model. The model that we will present as the integrating model is the one that we will have to define. Indeed, within our research, we want to compare models of corporate social responsibility management that we relate to the employment relationship. The companies met will therefore have to have a defined CSR model to be able to make a comparison. It is possible that the companies that will be chosen to participate in our research have CSR measures within the organization, but there is no model to support the theory. We want to go back and forth between theory and practice to define a model if it does not exist. We have established characteristics specific to the in-house model which will be grouped together with the literature and the known models described above. The following characteristics will be considered when designing the CSR management model:

a. The content of CSR measures

b. The level of importance of the components of CSR

c. Temporality

d. Social pressure

The factors that influence the determination of the integrating model will be established from the social responsibility management models proposed by Carroll, Pasquero and the ISO 26000 Standard. The integrating model is shown schematically in Figure 1. We will also consider the content of the CSR measures, the level of importance of the CSR components for employees, the timing of the application of the measures as well as the social pressure that can be linked to the CSR components.

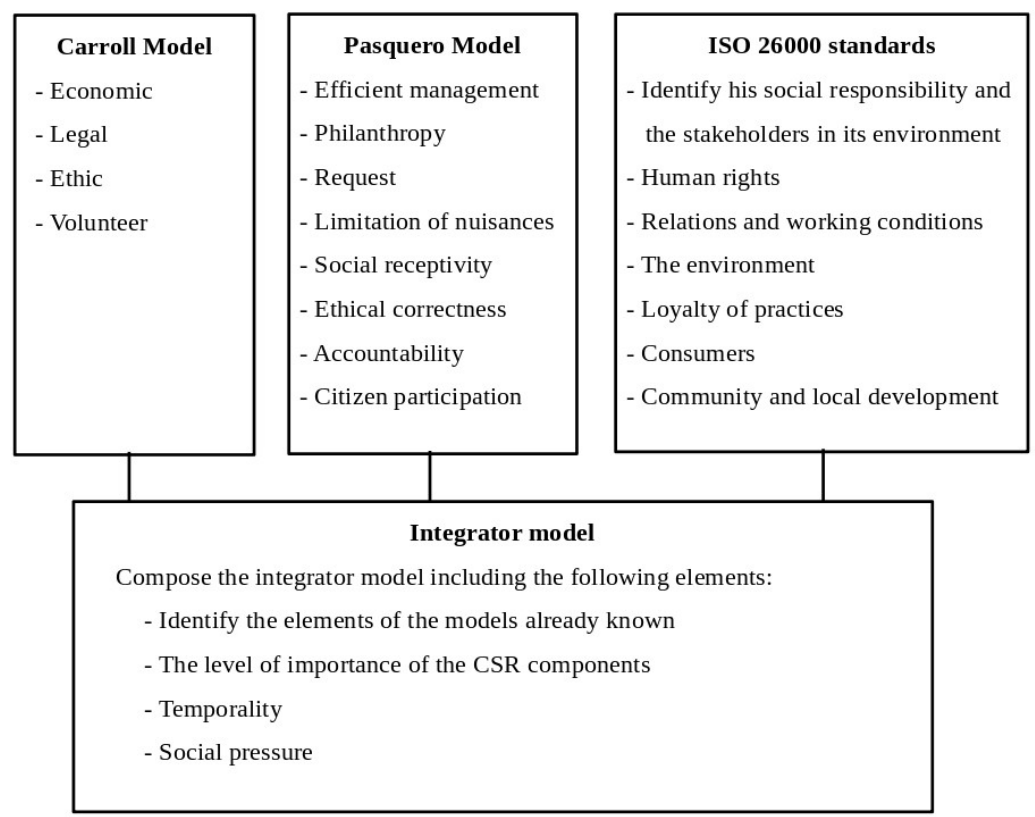

Figure 1: The integrative research model

We can see that within the integrative model, the aspects, level of importance of the CSR components, the temporality as well as the social pressure have been inscribed in blue. This change in color in the figure serves to identify our contribution to the design of the integrating model. Indeed, it is these distinctive aspects that will be used to design the 
models of corporate responsibility management that we will approach in the context of our study.

This is how, based on the documentation available in the company and following interviews with executives and employees, we will be able to define a model for managing corporate social responsibility. Indeed, we will be able to establish the CSR measures identified in the company and assess the level of importance that employees attribute to these measures. Also, we will want to know when the measures are put in place or are in effect. Do the measures come from social pressure or from the initiative of employers?

Also, as part of the integrative model, the different elements of CSR models in the literature have been included.

As part of our research, we will therefore work with the elements identified as being the elements retained to build the CSR management models.

\subsection{Perception of the employment relationship quality}

The second part of the research is based on the perception of the quality of the employment relationship. The models presented by Bordu et al. (2016) on the quality of life at work as well as Ashfort and Mael's (1989) categorization of social identity will help us to define this perception of the quality of the employment relationship. Figure 2 represents the diagram of our conception of the employment relationship.

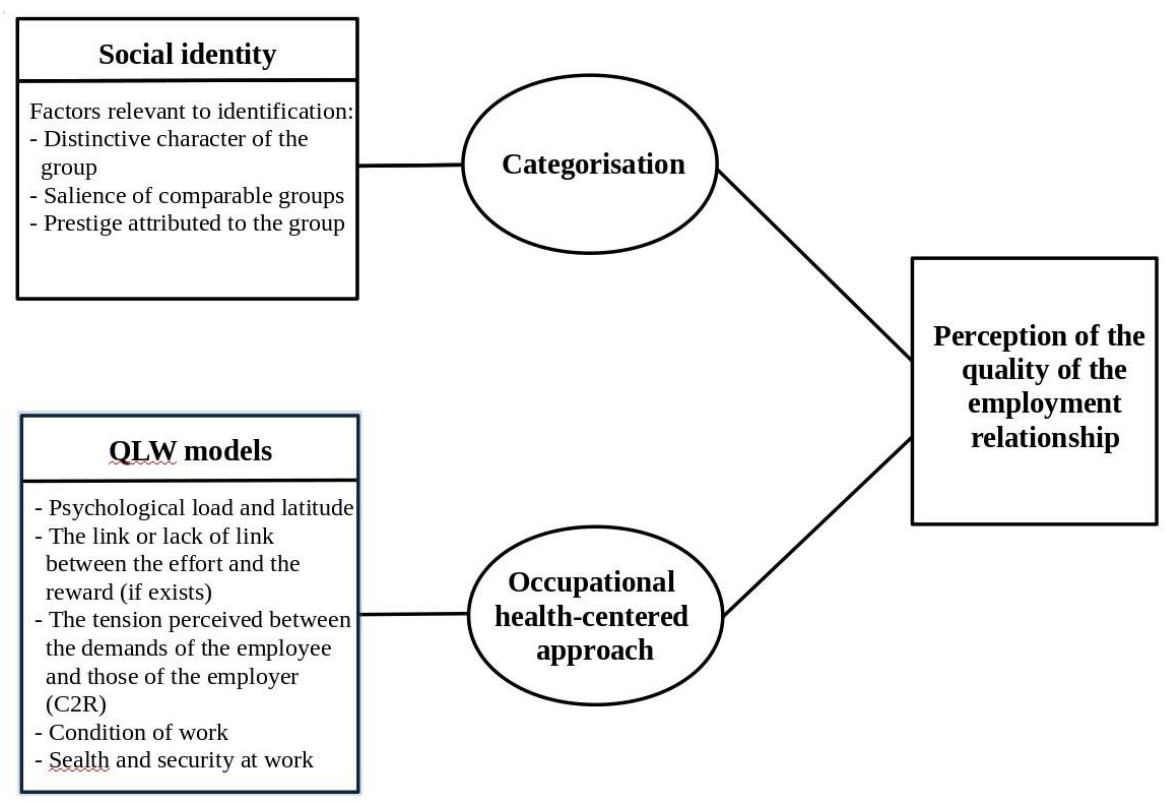

Figure 2: Perception of the quality of the employment relationship based on social identity and the quality of life at work.

Once again, in the diagram of the perception of the quality of the employment relationship, we can notice that different elements of the literature on the quality of life at work and social identity have been inscribed in orange. This particularity aims to demonstrate the aspects that we will retain more during our research, always with the aim of marking out our field of research.

We have chosen to retain the various elements since we believe that they can be linked to the various CSR management models that we can study in companies. Indeed, it will be 
interesting to see or not whether the CSR measures applied make employees feel as belonging to a distinctive group and whether they associate a certain prestige with this reference group. On the other hand, can adequate human resources management measures, such as a link between effort and reward or even working conditions, contribute to better implementation of CSR? Or is it the CSR management model that allows for better working conditions and a link between effort and reward?

Schill et al. (2018) argue that "according to the theory of psychological distance, corporate social responsibility is spatially and temporally close to the employee. Indeed, through the actions, reports and relations developed with stakeholders, the concept of CSR refers to a concrete concept and pertaining to the daily life of the employee"(2018, paragraph 5). CSR measures would therefore be more easily perceived by employees than other more abstract actions. It will be interesting to validate or not this idea. Does social responsibility allow the worker to develop a stronger organizational identification? Could CSR practices be seen as a lever for the perception of the quality of life at work?

We already know that a relationship seems to exist between an individual's social identity and CSR. Indeed, based on the assumption that an individual wishes to share the same values as the company for which he works and that a link can improve self-esteem, we could assume that social responsibility measures could serve for a better organizational identity.

When it comes to the quality of life at work, the links that unite it with CSR seem to emerge naturally. It will be very relevant to confirm or deny this idea. Will the employees we interview have a favorable perception of their quality of work life when CSR measures are applied in the workplace?

We have therefore built a research model on which we wish to base our research. The next part of this work will serve to demonstrate the operating framework in which we wish to propose our study.

\section{Operating framework}

We will carry out a comparative case study between two distinct organizations to determine the influence of social responsibility management models on the perception of the employment relationship quality that we have chosen to determine as the organizational identification and the quality of life at work. We may believe that the companies participating in our research will not have a clearly defined social responsibility management model. On the other hand, we will identify their model based on the models described in the literature. We can use other aspects that characterize CSR management models such as temporality, importance, and social pressure to define the models.

To understand the influence of the CSR management model, we therefore plan to focus our study on two companies with different social responsibility management models, placed in Quebec Region of Abitibi-Témiscamingue. In this way, we will be able to determine, for these specific cases, the influence of the CSR models on employees' perception of social identity and quality of life at work. Do the models supported by companies influence employees' perception of their organization? And how does this perception intervene in the employment relationship?

First, the operating framework and methodology will be presented to determine our methodological approach. We will also discuss the choice of a comparative case study to carry out our research project including the sampling strategy, the data collection method as well as the data analysis method that will be favored. Finally, the criteria of scientificity and ethical considerations will be discussed.

\subsection{Methodological approach}

As we wish to link the management of corporate social responsibility with the management of the employment relationship, we will favor qualitative research to clearly identify the 
feelings of workers. Watson and Frost $(2018,2011)$ claim that qualitative research generates information that is very detailed, to describe a specific situation. Also, there is still no validated CSR measurement scale, which may explain our choice to opt for qualitative research.

The determined research approach is the case study. Fortin (2010) recognizes the methodological contribution of the case study in the in-depth examination of a phenomenon. The case study is an empirical research approach that consists of investigating a phenomenon, an event, a group, or a set of individuals, selected in a non-random way, in order to realize a precise description and an interpretation that goes beyond its terminals (Roy, 2009, p. 207). Since the aim of the study is to better understanding the influence of the CSR management model on the perception of the employment relationship quality, the comparative case study should be retained. In fact, to identify elements related to the perception of workers, a comparative case study makes it possible to compare two different CSR management models and to assess the level of perception of the quality of the employment relationship referring to it. The case study is already widely recognized by the scientific community for its contribution to the understanding of factors that are difficult to measure (Roy, 2009). As the elements of our research are mainly based on perceptions evoked by employees, the case study seems ideal to us for analyzing factors that are difficult to measure.

\subsection{Method of data collection}

To be able to compare models of corporate social responsibility management, two organizations in Abitibi-Témiscamingue that have implemented socially responsible measures will be targeted. A first sample made up of management staff in each of the companies will help define the CSR management model favored by the organization. Within each of the organizations, these meetings will make it possible to build the integrative model of CSR management in place. We wish to meet at least one executive person per organization. Rational sampling is defined as the choice of subject that represents typical characteristics. (Fortin, 2010). Since we want to obtain management information, we necessarily must interview senior staff.

A second sampling targeting employees will be carried out. A stratified sampling method could ensure that we have a representative sample of our study population (Gavard-Perret et al., 2012, p.146). Since we want to have a bird's eye view of the organization, we will try to get respondents from various departments. We will also use as a criterion the distribution of the population, the gender of the employee, his age, and his seniority within the organization. We will consult with management to have a comprehensive portrait of the organization's employees and a list of them. Once the criteria have been selected, we will proceed by simple random sampling.

In the context of this study, we will use two types of data. The first consists of consulting the documentation that can help us identify the integrative model of CSR management in the organization. This can be internal documentation such as human resource management policies or social responsibility if they exist. The second type of data will be interview transcripts. Individual semi-structured interviews will be conducted by the researcher. We plan to do a minimum of 9 interviews per organization regarding employees, for a total of 18 interviews. We will be using the saturation theory which suggests that we will stop the interviews when the interviews bring nothing new as information, when the collected data is saturated. (Flick, 2009, p.138).

\subsection{Data collection tools}

In the context of this study, we will use two types of data. The first consists of consulting the documentation that can help us identify the integrative model of CSR management in the organization. This can be internal documentation such as human resource management policies or social responsibility if they exist. The second type of data will be interview 
transcripts. Individual semi-structured interviews will be conducted by the researcher. We plan to do a minimum of 9 interviews per organization regarding employees, for a total of 18 interviews. We will be using the saturation theory which suggests that we will stop the interviews when the interviews bring nothing new as information, when the collected data is saturated. (Flick, 2009, p.138)

Semi-structured interviews will be carried out directly at the employee's workplace if the situation allows. Indeed, during the interviews, if the standards of physical distancing are still in place, interviews by Zoom may be offered. Interviews will last approximately one hour per participant. Semi-structured interviews should be built around themes and use openended questions to encourage the respondent to engage. (Flick, 2009, p.156).

During the interviews, the order of the themes and questions discussed must remain flexible. The researcher must rely on the respondent's natural flow of ideas to evoke one theme or another. The formalization of the interview guide in the form of a topic to be addressed promotes a comparative analysis that can be carried out when the interviews are completed (Gavard-Perret, 2012).

\subsection{Data analysis method}

Following each meeting, we will produce the verbatim, the coding and carry out a preliminary analysis. In the content analysis, we will re-order by topic to facilitate the comparison of groups. (Gavart-Perret et al. 2012, p.282). Documentation should be indexed subsequently to facilitate the search for pages or themes, for example.

The last step of our analysis should consist in comparing the research results between the two organizations we met. These comparisons will allow us to write research results based on our study question.

\subsection{Scientific criteria and ethical considerations}

The validation of qualitative methods refers to the capacity to produce results having a value insofar as they contribute in a significant way to better understand a reality, a phenomenon studied. (Mucchielli 1996, p.265). The work of Lincoln and Guba (1985) proposes four criteria considered to be the reference in scientific evaluation of qualitative research. Credibility, portability, transparency, and internal consistency will be addressed as part of our study.

Regarding the ethical consideration, under the ethics and research policy (2012) of Université du Quebec en Abitibi-Témiscamingue, we must obtain the consent of the participants in our research project. This consent must be informed, free and continuous. That is, participation in the study must be voluntary and participants have the right to withdraw at any time without any justification (Bouchard and Cyr, 2011). A consent form will be presented to each study participant before each of our interviews. Also, to avoid an appearance of conflict of interest, the researcher will not be able to interview people he knows (Bouchard and Cyr, 2011).

Also, to protect the anonymity of study participants, a fictitious number will be assigned to each. The recordings of the interviews will be transcribed in complete confidentiality. Also, written material derived from participant data will be stored on a password protected computer for a period of five years. At the end of this period, everything will be destroyed. Under no circumstances will information on research participants be transmitted to any person or institution other than the researcher and his research director.

As the likelihood and magnitude of possible harms arising from participation in research are not greater than those of harms inherent in aspects of the participant's daily life associated with the research project, this research is considered below the threshold of minimal risk (Interagency Research Ethics Advisory Group, 2010, p.24). 


\section{Selective References}

1. Bourdu, É. (2016). La qualité de vie au travail: un levier de compétitivité : refonder les organisations du travail. Presses des Mines.

2. Carroll, A. B. (1979b). A Three-Dimensional Conceptual Model of Corporate Performance. Academy of Management Review, 4(4), 497 505. https:

3. Colle, R., Corbett-Etchevers, I., Defélix, C., Perea, C., \& Richard, D. (2017). Innovation et qualité de vie au travail: les entreprises «libérées" tiennent-elles leurs promesses? Management Avenir, $N^{\circ}$ 93(3), 161-183.

4. Djabi, M., \& Chanlat, J.-F. (2014). L'identification à l'organisation en contexte de changement. Revue francaise de gestion, $N^{\circ} 238(1)$, 33-58.

5. Igalens, J., Akremi, A. E., Gond, J.-P., \& Swaen, V. (2011). La responsabilité sociale des entreprises vue par les salariés: phare ou rétroviseur? Revue de gestion des ressources humaines, $N^{\circ} 82(4)$, 33-45.

6. Turcotte, M.-F. (2018). La responsabilité sociétale de l'organisation : exercices, cas et fondements (aleph_udq031970885; 2e édition.). Presses de l'Université du Québec. 